\title{
Preparation of Zinc Oxide Nanomaterial and Research and Development of Antibacterial Property
}

\author{
Jia Huang \\ School of Environment Design, Hunan International Economics University, Changsha 410205, China
}

Corresponding Author Email: huangjia1204@163.com

https://doi.org/10.18280/acsm.450507

Received: 13 July 2021

Accepted: 20 August 2021

\section{Keywords:}

zinc oxide $(\mathrm{ZnO})$ nanomaterial, preparation, antibacterial property, children's furniture

\begin{abstract}
Children using environmentally unfriendly furniture are more likely to suffer from allergic rhinitis, respiratory infections, and leukemia. The green design of children's furniture must consider anti-formaldehyde, deodorant, antibacterial, and antiviral factors. This paper prepares a zinc oxide $(\mathrm{ZnO})$ nanomaterial for children's furniture, and researches and develops the antibacterial property of the nanomaterial. The main contents include the synthesis method and preparation process, material morphology and structure characterization, and antibacterial performance testing. The practical substrate modification of the material was realized by pre-depositing polydopamine particles. In this way, the $\mathrm{ZnO}$ nanomaterial could apply to a wider range of children's furniture, become more durable, and realize efficient multi-mechanism synergistic sterilization. Experimental results show that the prepared material has a good antibacterial property.
\end{abstract}

\section{INTRODUCTION}

Green living is an increasingly popular concept. Safe and high-quality green furniture, especially children's wooden furniture, has become the core demand of consumers [1-6]. Children using environmentally unfriendly furniture are more likely to suffer from allergic rhinitis, respiratory infections, and leukemia [7-12]. The green design of children's furniture must consider all the factors that might endanger their health, such as anti-formaldehyde, deodorant, antibacterial, and antiviral factors [13-17]. Zinc oxide $(\mathrm{ZnO})$ nanomaterial provides a special paint for children's furniture, enabling functions like sterilization, health care, formaldehyde removal, stain resistance, and anti-aging.

Hermida-Montero et al. [18] reported the in vitro antifungal activity of $\mathrm{ZnO}$ nanoparticles against three symbiotic fungi of ragweed beetle, and studied the coating and particle size of two types of $\mathrm{ZnO}$ nanoparticles on antifungal activity. Experiments show that, although nanoparticle size is a key parameter, the coating of $\mathrm{ZnO}$ nanoparticles is the leading contributor to antifungal performance. La et al. [19] prepared $\mathrm{ZnO}$ nanoparticles by hydrothermal method, and characterized them by scanning electron microscopy (SEM) and X-ray diffraction (XRD). The prepared $\mathrm{ZnO}$ nanoparticles showed good antibacterial properties against several bacteria, including Staphylococcus aureus, Escherichia coli and Bacillus subtilis. Li et al. [20] presented a simple method for preparing superhydrophobic coatings based on acrylic resins: $\mathrm{ZnO}$ nanoparticles are modified with silane to obtain hydrophobic $\mathrm{ZnO}$, which is uniformly blended with acrylic resin, and then the mixture is sprayed onto the aluminum plate, forming a cured coating. Experimental results verify that the antibacterial performance of the $\mathrm{ZnO}$ nanoparticles/acrylic resin superhydrophobic coating is much better than pure acrylic resin coating.

The hydrophobicity and color stability are important features of wood. When wood is used as a raw material for outdoor products, these features are easy to change, thereby shortening the service life of the wood. Tuong et al. [21] adopted a two-step simple spraying method to apply $\mathrm{ZnO}$ coating to benzoin wood, aiming to improve hydrophobicity and color stability of the wood, the hydrophobicity and firmness of the coating, and the color stability of uncoated wood samples. Then, they evaluated the coated wood samples. Pang et al. [22] prepared $\mathrm{A} \mathrm{ZnO} / \mathrm{TiO}_{2}$ nano-array coating through hydrothermal synthesis and low-temperature liquid phase method. In vitro antibacterial experiments show that the bacterium has a maximum inhibitory rate of $99 \%$ against Staphylococcus aureus and 90\% against Escherichia coli.

This paper focuses on the preparation of a $\mathrm{ZnO}$ nanomaterial for children's furniture, and the research and development of antibacterial property. The main contents are as follows: After summing up the strengths and defects of $\mathrm{ZnO}$ nanomaterial, Section 2 specifies the principle and flow of preparing Zinc nano-array for high-temperature hard materials like metal handles, and wooden plates in children's furniture, respectively, and analyzes the antibacterial mechanism and antibacterial performance of the zinc nano-array. Section 3 improves the enrichment of $\mathrm{ZnO}$ nanocrystals on cellulose by pre-depositing polydopamine particles, and explains the process of antibacterial performance determination and thermogravimetric analysis. Section 4 carries out comparative experiments to demonstrate the good antibacterial property of the prepared modified material.

\section{PREPARATION AND ANTIBACTERIAL PROPERTY OF ZNO NANO-ARRAY}

\subsection{Preparation and characterization}

Whether the environment is bright or dark, the $\mathrm{ZnO}$, as an active oxide produced by catalytic reaction, always has an 
excellent antibacterial effect. However, the chemical antibacterial mechanism depends on the release of active oxygen, and generally faces problems like the slow active effect, the short life of active oxides, the potential microbial mutation, and the development of drug resistance. To solve these problems, it is particularly important to find a new antibacterial method. Inspired by the physical sterilization of bionic nanostructures, some scholars have constructed $\mathrm{ZnO}$ nano-arrays, which not only pierce through bacteria, but also achieve significant photocatalytic self-cleaning and functional regeneration.

Taking nano- $\mathrm{ZnO}$ array as the object, this paper describes the synthesis method and the preparation process of nano- $\mathrm{ZnO}$ array, characterizes the morphology and structure of the material, and changes and modifies the practical substrate. In this way, the $\mathrm{ZnO}$ nanomaterial could apply to a wider range of children's furniture, become more durable, and realize efficient multi-mechanism synergistic sterilization. Tables 1 and 2 list the reagents and instruments/equipment of our experiments.

$\mathrm{ZnO}$ has multiple crystal structures. The hydrothermal method of $\mathrm{ZnO}$ nano-array includes three primary stages: the preparation of the precursor solution of the seed layer, the preparation of the seed layer, and the generation of the nanoarray. For high-temperature hard materials like the metal handles of children's furniture, the pulling method can be adopted to generate a $\mathrm{ZnO}$ array on a clean and dry rigid substrate. During the generation, the required crystal ion $\mathrm{Zn}^{2+}$ is provided by zinc nitrate hexahydrate, and the required $\mathrm{OH}^{-}$ is supplied by the hydrolysis of hexamethylenetetramine. The specific reactions are described by:

$$
\begin{gathered}
6 \mathrm{H}_{2} \mathrm{O}+\left(\mathrm{CH}_{2}\right)_{6} \mathrm{~N}_{4} \rightarrow 4 \mathrm{NH}_{3}+6 \mathrm{HCHO} \\
\mathrm{H}_{2} \mathrm{O}+\mathrm{NH}_{3} \rightarrow \mathrm{OH}^{-}+\mathrm{NH}_{4}^{+}
\end{gathered}
$$

Table 1. Reagents

\begin{tabular}{ccc}
\hline Name & Specification & Manufacturer \\
\hline Dihydrate zinc nitrate & Analytically pure & Tianjin Guangfu (China) \\
Sodium hydroxide & Analytically pure & Tianjin Fengchuan (China) \\
Isopropanol & Analytically pure & Tianjin Yingcheng (China) \\
Dihydrate ammonium acetate & Analytically pure & Tianjin Guangfu (China) \\
Absolute ethyl alcohol & Analytically pure & Tianjin Yingcheng (China) \\
Hexamethylenetetramine & Analytically pure & Tianjin Fengchuan (China) \\
Polyethylene glycol octylphenyl ether & Analytically pure & Tianjin Fengchuan (China) \\
Citric acid & Analytically pure & Tianjin Fengchuan (China) \\
Triethylamine & Analytically pure & Tianjin Fengchuan (China) \\
Bacterial cellulose & Food grade & Hainan Yide (China) \\
\hline
\end{tabular}

Table 2. Instruments and equipment

\begin{tabular}{ccc}
\hline Name & Manufacturer & Model \\
\hline Electronic balance & Adam Equipment, Wuhan (China) & PWC124 \\
Thermal field emission scanning electron microscope & OLimp (Japan) & TF2000 \\
High-temperature and high-pressure autoclave & Jiangyin Binjiang (China) & YK-24HDD \\
Freeze dryer & Ningbo Scientz (China) & SCIENTZ-10N \\
Electro-heating standing-temperature cultivator & Shanghai Yuejin (China) & HH.B-S \\
Constant temperature water bath & Gonyi Yuhua (China) & CH1015 \\
High-speed refrigerated centrifuge & Eppendorf (Germany) & 3 S10R \\
Water bath oscillator & Haimen Kylin-Bell (China) & QL-901 \\
X-ray diffractometer & Rigaku (Japan) & D/MAX-2500 \\
Cell incubator & Thermal Fisher Scientific (United States) & Therme371 \\
Thermal gravimetric analyzer & Netzsch (Germany) & STA4499F3 \\
Universal testing machine & Instron (United States) & Instron3369 \\
Electric furnace & Beijing Zhongxingweiye (China) & DL-1 \\
\hline
\end{tabular}




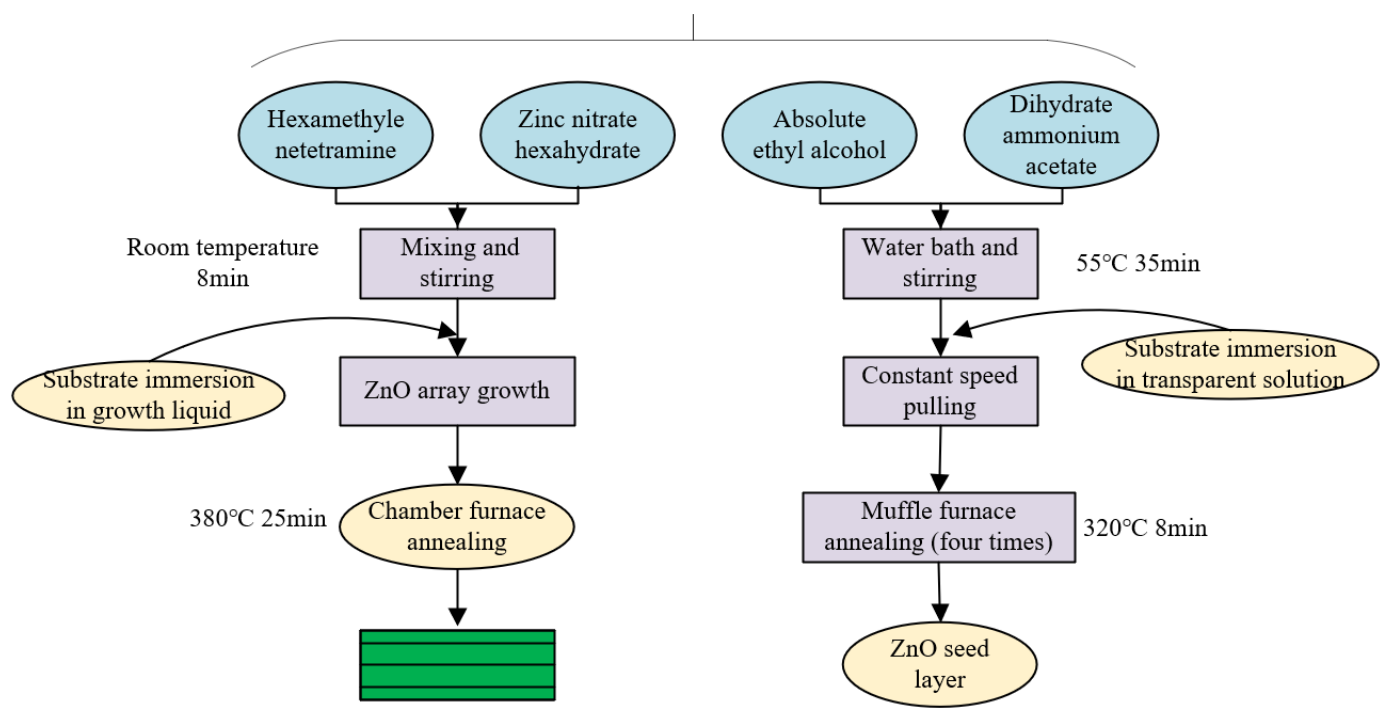

Figure 1. Experimental flow of high-temperature hard materials

$$
\begin{gathered}
\mathrm{Cell} \cdot \mathrm{O} \cdot \mathrm{Zn}(\mathrm{OH})_{4}^{3-} \rightarrow \mathrm{H}_{2} \mathrm{O}+\mathrm{Cell} \cdot \mathrm{O} \cdot \mathrm{ZnO} \\
2 \mathrm{OH}^{-}+\mathrm{Zn}^{2+} \rightarrow \mathrm{Zn}(\mathrm{OH})_{2} \\
2 \mathrm{OH}^{-}+\mathrm{Zn}(\mathrm{OH})^{2} \rightarrow \mathrm{Zn}(\mathrm{OH})_{4}^{2-} \\
\mathrm{Zn}(\mathrm{OH})_{4}^{2-}+\mathrm{Zn}(\mathrm{OH})_{4}^{2-} \rightarrow 4(\mathrm{OH})^{-}+2 \mathrm{H}_{2} \mathrm{O}+2 \mathrm{ZnO} \downarrow
\end{gathered}
$$

The structure of the obtained $\mathrm{ZnO}$ crystals was characterized by an X-ray diffractometer at room temperature. Let MG be the mean grain size; $\psi$ be the X-ray wavelength; $\alpha$ be half peak width; $\omega \in\left[3,45^{\circ}\right]$ be the Bragg diffraction angle. Then, the mean grain size of $\mathrm{ZnO}$ can be calculated by:

$$
M G=0.89 \psi /(\alpha \cos \omega)
$$

Let $Q_{C}$ be the number-average molecular weight; $Q_{H}$ be the weight-average molecular weight. Tetrahydropyrane and polystyrene were selected as the solvent and the standard sample, respectively. Then, a gel permeation chromatographic analyzer was employed to measure the $Q_{C}$ and $Q_{H}$ of the obtained $\mathrm{ZnO}$ crystals. The polydispersity index can be calculated by:

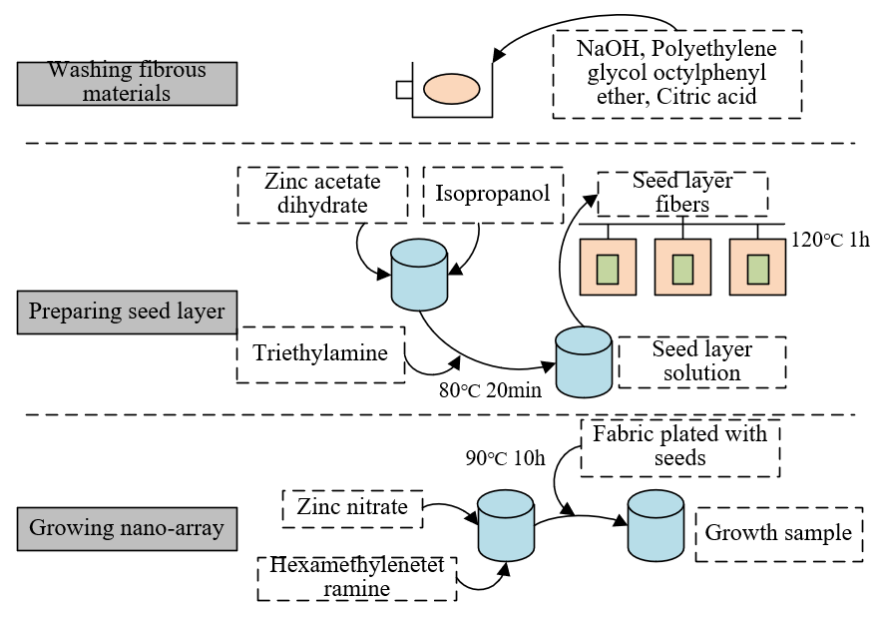

Figure 2. Experimental flow of fibrous materials

$$
P D I=\frac{Q_{H}}{Q_{C}}
$$

Let $\varepsilon$ be the mean grain diameter; $\psi_{1 / 2}$ be the wavelength at the excitation peak or the half-absorption position. Based on the empirical relationship between $\varepsilon$ and $\psi_{1 / 2}$ of $\mathrm{ZnO}$, the particle size of $\mathrm{ZnO}$ crystals can be calculated by:

$$
\frac{1240}{\psi_{1 / 2}}=3.301+\frac{294.0}{\varepsilon^{2}}+\frac{1.09}{\varepsilon}
$$

Let $\mathrm{RQ}_{\mathrm{ZnO}}$ be the recovery mass of $\mathrm{ZnO}$ nanocrystals. Then, the yield $\eta$ of $\mathrm{ZnO}$ nanomaterials can be calculated by:

$$
\eta=\frac{R Q_{\mathrm{ZnO}}}{R Q_{\left(\mathrm{CH}_{2}\right)_{6} \mathrm{~N}_{4}, 6 \mathrm{H}_{2} \mathrm{O}}+R Q_{\mathrm{NH}_{3}, \mathrm{H}_{2} \mathrm{O}}+R Q_{\mathrm{OH}^{-}}+R Q_{\mathrm{Zn}(\mathrm{OH})_{2}}}
$$

\subsection{Determination of antibacterial property}

The active carboxyl content of cellulose was determined according to the standard TAPPI T237 cm-98. Firstly, a proper amount of cellulose was taken from flexible fibrous materials, treated in hydrochloric acid solution for $2 \mathrm{~h}$, and flushed with deionized water. Then, $\mathrm{NaHCO}_{3}-\mathrm{NaCl}$ solution was quickly added to the conical flash containing the filtrate. After $1 \mathrm{~h}$ of reaction, Methyl red indicator was added to the filtrate. Finally, titration was carried out based on hydrochloric acid solution. Let $\mathrm{E}$ and $\mathrm{F}$ be the hydrochloric acid solution used for titrating the filtrate, and for titrating the $\mathrm{NaHCO}_{3}-\mathrm{NaCl}$ solution, respectively; $\mathrm{G}$ be the mass of water in the wet slurry cake obtained through the flushing by deionized water; $\mathrm{P}$ be the actual concentration of the hydrochloric acid solution; $\mathrm{Z}$ be the absolute dry mass of the cellulose sample. Then, the active carboxyl content of cellulose can be calculated by:

$$
C A S=\{F-[E+(E \times G / 50)]\} \times P \times(200 / Z)
$$

The nitrogen content in and on the zinc acetate solution film were measured by an elemental analyzer. Since $\mathrm{ZnO}$ nanomaterials contain no nitrogen, the nitrogen must come from the chitosan of cellulose. Let $\mathrm{W}$ and $\mathrm{D}$ be the mass of the 
zinc acetate solution film before and after flushing, drying, and annealing, respectively. Then, the mass percentage of chitosan on the surface of zinc acetate solution film can be calculated by:

$$
C S \%=D / W \times 100 \%
$$

Next, Botrytis cinerea, Escherichia coli, and Staphylococcus aureus of cell density $1 \times 10^{6} / \mathrm{mL}$ were inoculated to the crystallized cellulose substrate. On the $1^{\text {st }}$ and $3^{\text {rd }}$ of curing, cell counting was performed with a Cell Counting Kit-8 (CCK-8). Let EGAV and NGAV be the absorbance value of the experimental group, and the absorbance value of the negative group, respectively. Then, the relative cell proliferation rate can be calculated by:

$$
R C P R=E G A V / N G A V \times 100 \%
$$

The diffusion and growth scope of different colonies on each substrate was measured by a vernier caliper. Let $\mathrm{GR}_{\mathrm{O}}$ be the mycelial growth range of the reference substrate, and $\mathrm{GR}_{\mathrm{F}}$ be that of the substrate containing the $\mathrm{ZnO}$ nano-array. Then, the bacteriostasis rate $\eta_{\mathrm{IR}}$ of $\mathrm{ZnO}$ nano-array on each colony can be calculated by:

$$
\eta_{I R}=\frac{G R_{O}-G R_{F}}{G R_{O}} \times 100 \%
$$

\section{PREPARATION PROPERTIES OF NANOMATERIALS \\ AND ANTIBACTERIAL MODIFIED ZNO}

\subsection{Preparation and characterization}

The dopamine polymer with functional group like primary amine and indole is strongly adhesive and universally applicable. It can deposit on polymers, hard materials, and flexible fibrous materials. If a flexible fibrous material is predeposited with polydopamine, the $\mathrm{ZnO}$ nanocrystals will concentrate on the cellulose more apparently.

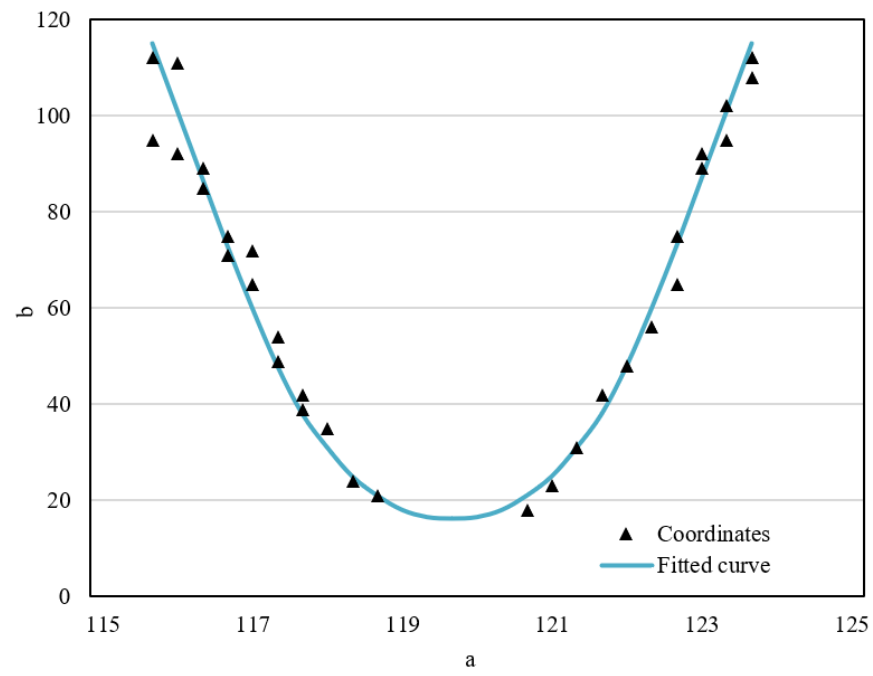

Figure 3. The curve fitted by GaussAMP function

To further determine the relative content of $\mathrm{ZnO}$ nanocrystals produced before and after the pre-deposition of polydopamine particles, this paper carries out a mathematical statistical analysis on $\mathrm{ZnO}$ nanocrystals based on image processing techniques. Firstly, Photoshop was adopted to uniformly take several pixels from the $\mathrm{ZnO}$ nano-array. Then, the coordinates of each pixel were imported to the function plotting tool Origin 8.5 to draw scatterplots. Finally, each pixel was fitted. The GaussAMP function is employed here:

$$
b=b_{0}+\delta e^{-\frac{\left(a-a_{v}\right)^{2}}{2 q^{2}}}
$$

The curve fitted by GaussAMP function is shown in Figure 3 , where $a \in(-2.2,2.2) ; b_{0}, \delta$, and $2 q^{2}$ equal $-274562,336452$, and 57425 , respectively.

Under room temperature, the difference between the two crystal faces before and after the pre-deposition of polydopamine particles can be obtained using $\mathrm{ZnO}$ nanocrystal parameters. The difference was characterized by the idea of calculus. Let $\mathrm{T}$ and $\mathrm{T}^{\prime}$ be the number of $\mathrm{ZnO}$ nanocrystals before and after the pre-deposition of polydopamine particles, respectively; $\mathrm{u}$ and e be the total length and width of the exposed crystal surface, respectively. Then, the ratio of the exposed crystals before and after the predeposition of polydopamine particles can be calculated by:

$$
S=\frac{\sum T^{2} u e}{\sum T^{\prime 2} u e}
$$

\subsection{Determination of antibacterial property}

Concerning the antibacterial activity of nano-zinc oxide materials in darkness, this paper only considers the final products $\mathrm{H}_{2} \mathrm{O}_{2}$ and $\mathrm{O}_{2}^{-}$.

Following the $\mathrm{KI}$ oxidation-reduction titration, the $\mathrm{H}_{2} \mathrm{O}_{2}$ produced from the $\mathrm{ZnO}$ suspension was determined by measuring the absorbance with a visible spectrophotometer. The measurement was conducted in a completely dark environment. Let $\mathrm{XG}_{450}$ be the absorbance value at $450 \mathrm{~nm}$; v be the $\mathrm{H}_{2} \mathrm{O}_{2}$ content of the solution. Then, the linear regression equation for the standard curve between the $\mathrm{H}_{2} \mathrm{O}_{2}$ content and absorbance can be fitted as:

$$
X G_{450}=0.132 v-0.0065
$$

Let $V u$ and $V q$ be the $\mathrm{H}_{2} \mathrm{O}_{2}$ contents in u bottles and $q$ bottles of sample solution, respectively; $\mathrm{SO}$ be the sampling volume. Then, the yield of the active substance $\mathrm{H}_{2} \mathrm{O}_{2}$ in the suspension can be calculated by:

$$
v=\frac{9\left(V_{U}-V_{Q}\right)\left(X G_{450}+0.0065\right)}{0.6 \times 0.132 \times S O}
$$

The $\mathrm{O}_{2}^{-}$content was estimated by nitro blue tetrazolium. Let $\mathrm{XG}_{290}$ be the absorbance value at $290 \mathrm{~nm}$; $\mathrm{v}^{\prime}$ be the $O_{2}^{-}$content in the solution. Then, the linear regression equation for the standard curve between the nitro blue tetrazolium content and absorbance can be fitted as:

$$
X G_{290}=0.0421 v^{\prime}+0.01448
$$

Let $V u$ ' and $V q^{\prime}$ be the $O_{2}^{-}$contents in $u$ bottles and $q$ bottles of sample solution, respectively; SO' be the sampling volume. 
Then, the yield of the active substance $\mathrm{O}_{2}^{-}$in the suspension can be calculated by:

$$
v^{\prime}=\frac{9\left(V_{U}^{\prime}-V_{Q}^{\prime}\right)\left(X G_{290}+0.0077\right)}{0.45 \times 0.174 \times S O^{\prime}}
$$

Finally, the antibacterial activity of the prepare $\mathrm{ZnO}$ nanoparticles was verified in a dark environment, using three common type strains of the cell density $1 \times 10^{6} / \mathrm{mL}$ : Botrytis cinerea, Escherichia coli, and Staphylococcus aureus.

\subsection{Thermogravimetric analysis}

Let $\varphi_{\mathrm{CR}}$ and $\varphi_{\mathrm{AP}}$ be the diffraction peak area of the crystalline phase and the amorphous phase, respectively. The crystallinity of $\mathrm{ZnO}$ nanocrystals generated before and after the pre-deposition of polydopamine particles can be calculated by

$$
C R Y=\phi_{C R} /\left(\phi_{C R}+\phi_{A P}\right) \times 100 \%
$$

For the modified antibacterial material based on the prepared $\mathrm{ZnO}$ nanocrystals, the mechanical properties can be characterized by breaking strength. Let RI, BS, HD, and KD be the relative strength, breaking strength, thickness, and width of the material, respectively. Then, we have:

$$
R I=\frac{B S}{H D \times K D}
$$

To further explore the influence of nanoparticle properties over the thermal degradation of modified $\mathrm{ZnO}$ nanomaterials, this paper analyzes the modified antibacterial materials based on the thermal degradation reaction kinetics of modified materials. Let $P O_{s}, P O_{\tau}$, and $P O_{e}$ be the weights of the modified material at the start, at time $\tau$, and at the end of the thermal degradation reaction. Then, the weight loss rate of the modified material can be calculated by:

$$
\gamma=\frac{P O_{s}-P O_{\tau}}{P O_{s}-P O_{e}}
$$

The thermal degradation rate can be calculated by:

$$
\frac{d \gamma}{d \tau}=\Psi g(\gamma)
$$

According to the empirical formula of the relationship between chemical reaction rate and temperature, we have:

$$
\Psi=S H \cdot e^{-Q B_{c} / M G \xi}
$$

where, $\Psi$ is the rate constant; MG is molar gas constant, $\xi$ is thermodynamic temperature; $\mathrm{QB}_{\mathrm{C}}$ is apparent activation energy; $\mathrm{SH}$ is pre-exponential factor. Let $m$ be the number of reaction stages. The reaction mechanism of the modified material directly determines the function $\mathrm{g}(\gamma)$ in formula $(30)$ :

$$
g(\gamma)=(1-\gamma)^{m}
$$

$$
\frac{d \gamma}{d \tau}=S H \cdot e^{-\frac{Q B_{c}}{M G \xi}}(1-\gamma)^{m}
$$

Taking the log of both sides of formula (33) and finding differentials of $\mathrm{d} \gamma / \mathrm{d} \tau$, and $1-\gamma$ :

$$
\Delta \ln \left(\frac{d \gamma}{d \tau}\right)=-\frac{Q B_{c}}{3.15 S} \cdot d(1 / \xi)+m d \ln (1-\gamma)
$$

Formula (34) can be converted to a differential form:

$$
\Delta \ln \left(\frac{d \gamma}{d \tau}\right)=-\frac{Q B_{c}}{3.15 S} \cdot \Delta(1 / \xi)+m \Delta \ln (1-\gamma)
$$

Dividing both sides of formula (35) by $\ln (1-\gamma)$ :

$$
\frac{\Delta \ln (d \gamma / d \tau)}{\Delta \ln (1-\gamma)}=-\frac{Q B_{c}}{3.15 S} \cdot \frac{\Delta(1 / \xi)}{\Delta \ln (1-\gamma)}+m
$$

Since $d \gamma / d \tau=(d \gamma / d \xi) \times(d \xi / d \tau)$, we have:

$$
\frac{\Delta \ln (d \gamma / d \tau)}{\Delta \ln (1-\gamma)}=\frac{\Delta \ln (d \gamma / d \xi)}{\Delta \ln (1-\gamma)}
$$

That is:

$$
\frac{\Delta \ln (d \gamma / d \xi)}{\Delta \ln (1-\gamma)}=-\frac{Q B_{c}}{3.15 S} \cdot \frac{\Delta(1 / \xi)}{\Delta \ln (1-\gamma)}+m
$$

\section{EXPERIMENTS AND RESULTS ANALYSIS}

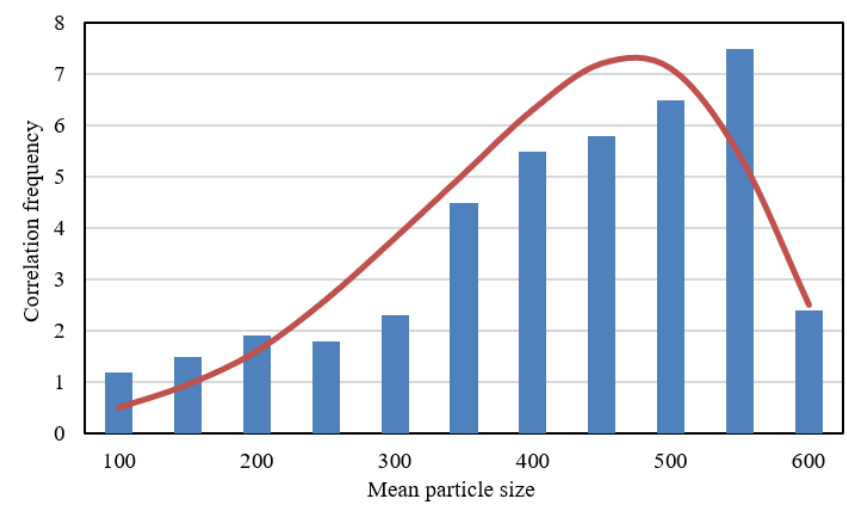

(a)

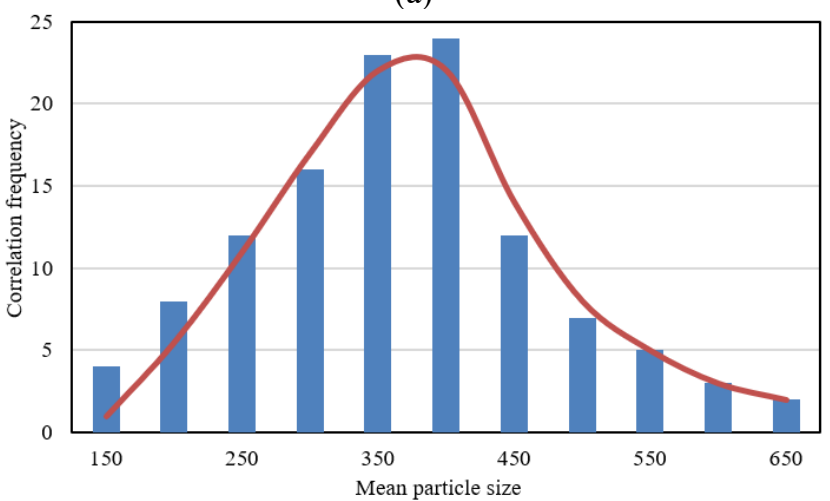

(b)

Combining formulas (30)-(32): 


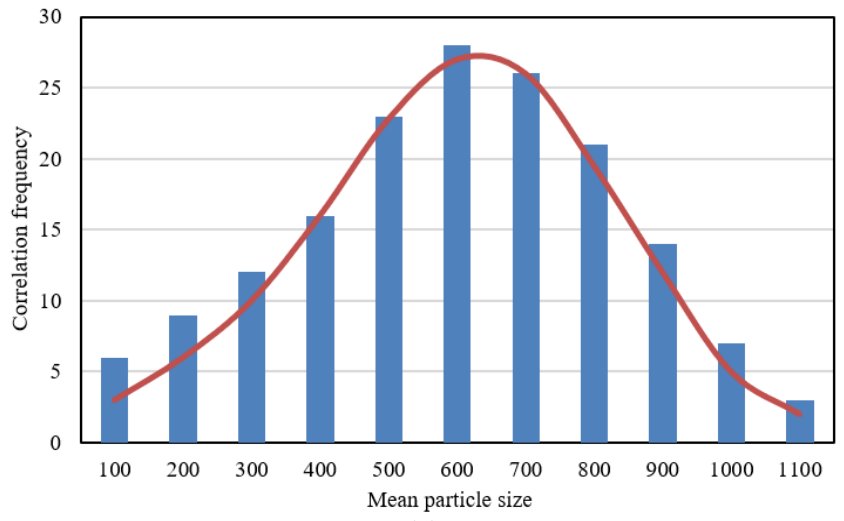

(c)

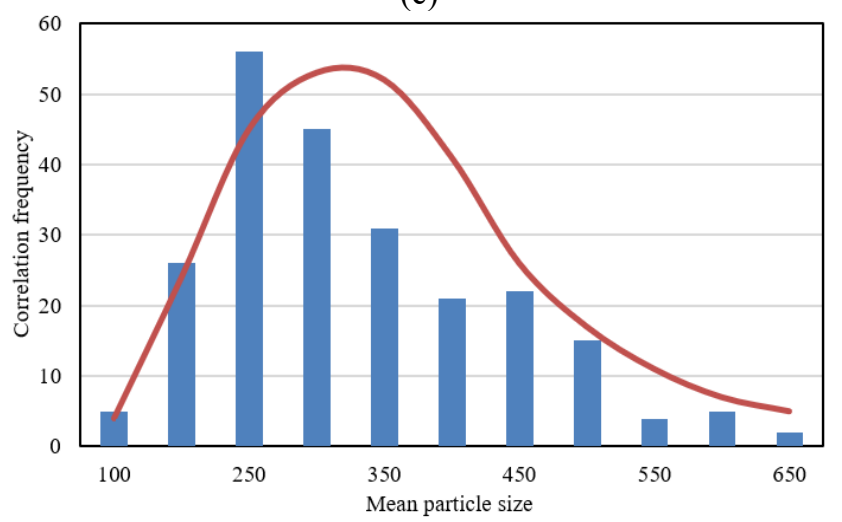

(d)

Figure 4. Particle size distribution of $\mathrm{ZnO}$ nanocrystals

Figure 4 shows the particle size distribution of the modified $\mathrm{ZnO}$ nanocrystals obtained with growth solution of different concentrations: $6 \mathrm{mmol} / \mathrm{L}, 12 \mathrm{mmol} / \mathrm{L}, 24 \mathrm{mmol} / \mathrm{L}$, and $30 \mathrm{mmol} / \mathrm{L}$. It can be seen that growth solution concentration significantly affected the particle size distribution of the $\mathrm{ZnO}$ crystals in the modified material. As the growth solution concentration increased from $6 \mathrm{mmol} / \mathrm{L}$ to $30 \mathrm{mmol} / \mathrm{L}$, the mean particle size of $\mathrm{ZnO}$ nanocrystals first increased and then gradually decreased. This means the rising concentration of the growth solution pushes up the zinc ion content, and the number of $\mathrm{ZnO}$ crystals. As a result, more active sites appear as zinc ions are absorbed by the cellulose substrate. When the growth solution reaches a certain concentration, the zinc ions outside the cellulose substrate are directly bonded, impeding the crystallization of $\mathrm{ZnO}$ on substrate surface. Hence, the number and mean particle size of $\mathrm{ZnO}$ crystals both dropped gradually.

Table 3 provides the statistics on the particle size and antibacterial property of $\mathrm{ZnO}$ nanocrystals with growth solution of different concentrations. The largest quantity and most antibacterial $\mathrm{ZnO}$ were observed at the growth solution concentration of $24 \mathrm{mmol} / \mathrm{L}$ and the particle size of $432.58 \mathrm{~nm}$, followed by $30 \mathrm{mmol} / \mathrm{L}$ and $395.26 \mathrm{~nm}$. The above statistics echo with the antibacterial rates on Botrytis cinerea, Escherichia coli, and Staphylococcus aureus.

Table 4 summarizes the molecular weight and yield of modified material samples at different recovery mass fractions of $\mathrm{ZnO}$ nanocrystals. It can be inferred that, with the growth of $\mathrm{ZnO}$ mass fraction, the molecular weight of the modified material decreased, that is, the ratio and concentration of the solvent negatively affect the molecular weight of the modified material. In addition, with the increase of the recovery mass fraction of $\mathrm{ZnO}$ nanocrystals, the yield of modified material samples decreased. The main reason is that the repeated flushing with denoised water wash away the impurities in the growth solution, namely, dopamine polymer and citric acid. Hence, the recovery mass fraction of $\mathrm{ZnO}$ nanocrystals should be controlled within 3\%. Figure 5 gives the XRD images and attenuated total reflection (ATR)- Fourier-transform infrared spectroscopy (FTIR) images of different modified material samples, which further validate the above conclusions.

Table 3. Particle size and antibacterial property of $\mathrm{ZnO}$ nanocrystals with growth solution of different concentrations

\begin{tabular}{ccccc}
\hline $\begin{array}{c}\text { Growth solution } \\
\text { concentration }\end{array}$ & $\mathbf{6}$ & $\mathbf{1 2}$ & $\mathbf{2 4}$ & $\mathbf{3 0}$ \\
\hline $\begin{array}{c}\text { Mean particle size } \\
\text { Probability of }\end{array}$ & 340.85 & 432.58 & 578.29 & 395.26 \\
effective antibacterial & $\begin{array}{c}5.28 \mathrm{E}- \\
06\end{array}$ & $\begin{array}{c}1.06 \mathrm{E}- \\
02\end{array}$ & 0.075 & $\begin{array}{c}6.02 \mathrm{E}- \\
01\end{array}$ \\
$\begin{array}{c}\text { ZnO } \\
\text { Number of effective } \\
\text { antibacterial ZnO }\end{array}$ & $\begin{array}{c}5.28 \mathrm{E}- \\
06\end{array}$ & 0.00445 & 0.69258 & 0.04685 \\
\hline
\end{tabular}

Table 4. Molecular weight and yield of different samples

\begin{tabular}{ccccccc}
\hline $\begin{array}{c}\text { Sample } \\
\text { number }\end{array}$ & $\mathbf{1}$ & $\mathbf{2}$ & $\mathbf{3}$ & $\mathbf{4}$ & $\mathbf{5}$ & $\mathbf{6}$ \\
\hline $\boldsymbol{Q}_{\boldsymbol{C}}$ & 24562 & 46253 & 35284 & 32648 & 32477 & 30254 \\
$\boldsymbol{Q}_{\boldsymbol{H}}$ & 36859 & 81549 & 66348 & 56984 & 56481 & 46251 \\
$\boldsymbol{P D I}$ & 1.47 & 1.78 & 1.82 & 1.76 & 1.72 & 1.55 \\
$\boldsymbol{\eta}$ & 53.4 & 95.4 & 93.4 & 82.4 & 53.4 & 28.7 \\
\hline
\end{tabular}

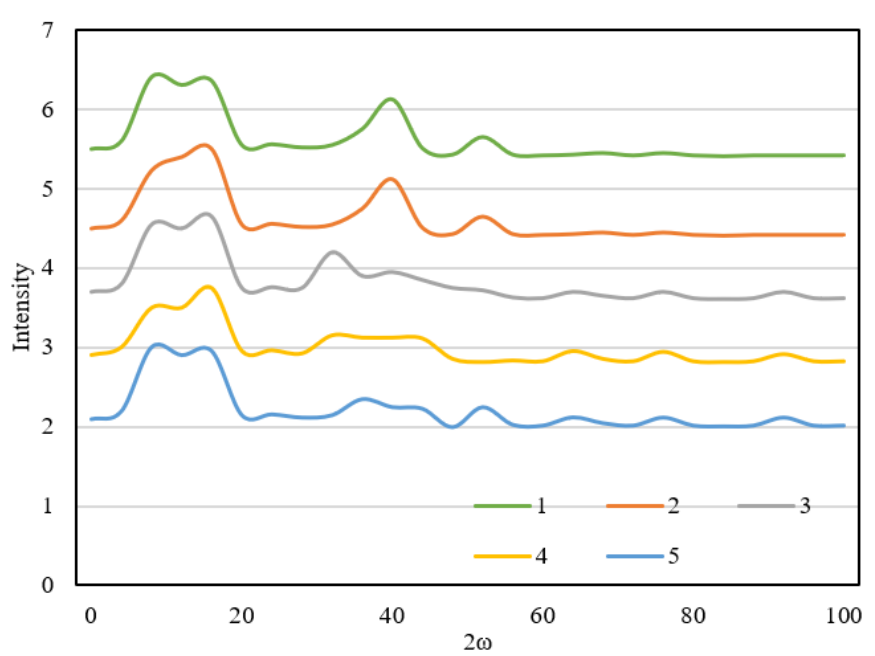

(a)

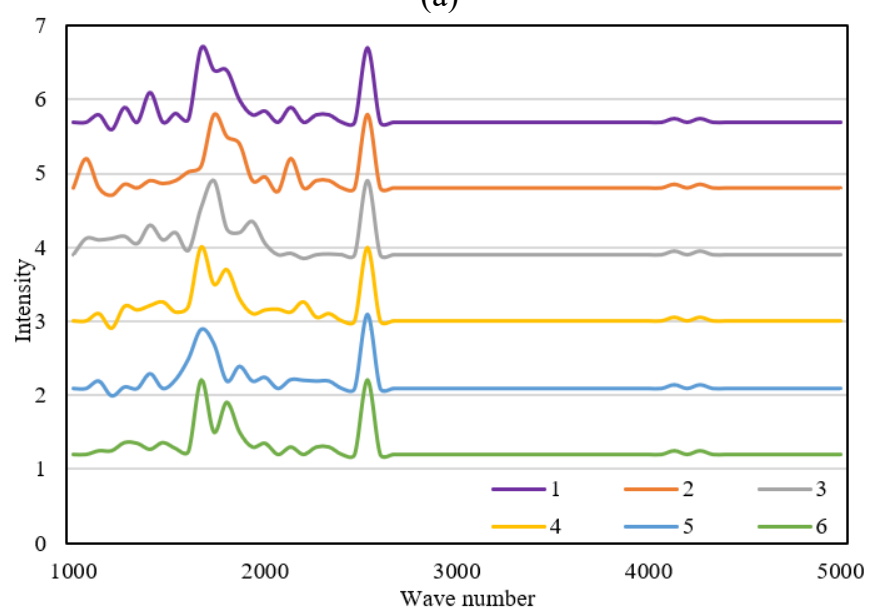

(b)

Figure 5. XRD and ATR-FTIR images of different modified material samples 


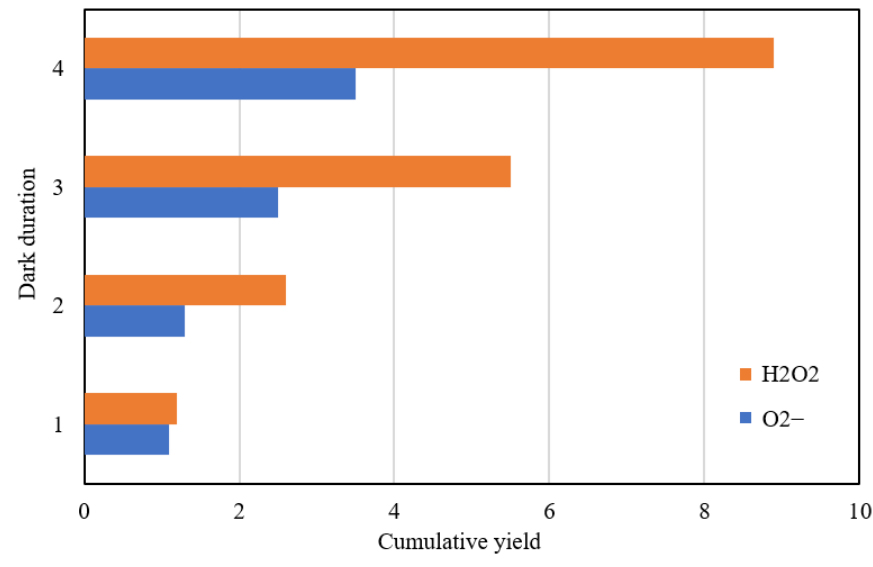

Figure 6. Cumulative yield of final products $\mathrm{H}_{2} \mathrm{O}_{2}$ and $\mathrm{O}_{2}^{-}$ under dark conditions

Table 5. The residual mass of the modified material with different mass losses at the temperature of $650^{\circ} \mathrm{C}$

\begin{tabular}{cccccc}
\hline \multicolumn{2}{c}{ Sample } & No polydopamine & $\mathbf{3 \%}$ & $\mathbf{5 \%}$ & $\mathbf{7 \%}$ \\
\hline Mass & $6 \%$ & 413.56 & 375.29 & 370.11 & 366.25 \\
loss $12 \%$ & 400.23 & 362.54 & 356.42 & 362.15 \\
$650^{\circ} \mathrm{C}(\%)$ & 0 & 2.14 & 4.74 & 5.59 \\
\hline
\end{tabular}

Three common type strains, namely, Botrytis cinerea, Escherichia coli, and Staphylococcus aureus, were selected to verify the antibacterial activity of the prepared $\mathrm{ZnO}$ nanomaterial under dark conditions. Figure 6 shows the cumulative yield of final products $\mathrm{H}_{2} \mathrm{O}_{2}$ and $\mathrm{O}_{2}^{-}$under dark conditions. It can be observed that the prepared $\mathrm{ZnO}$ nanomaterial can suppress nearly $99.9 \%$ of the bacteria. The minimal inhibitory concentration was 200,250 , and $300 \mathrm{mg} / \mathrm{L}$ against the three common type strains. The performance is better than any $\mathrm{ZnO}$ nanostructure material available in the market. Table 5 shows the residual mass of the modified material with different mass losses at the temperature of $650^{\circ} \mathrm{C}$. The results indicate that the pre-deposition of polydopamine improves the crystallinity of the modified material, and promotes the growth of $\mathrm{ZnO}$ nanocrystals. At $650^{\circ} \mathrm{C}$, the residual mass of the modified material was $2.14 \mathrm{~g}, 4.74 \mathrm{~g}$, and $5.59 \mathrm{~g}$, respectively, which is not very different from the actual dose.

The antibacterial activity of the prepared material, before and after the pre-deposition of polydopamine, against the three common type strains can be measured by the minimal inhibitory concentration. Figure 7 and Table 6 report the variation of minimal inhibitory concentration before and after pre-deposition of polydopamine. After the pre-deposition of polydopamine, the modified $\mathrm{ZnO}$ nanomaterial became stronger in antibacterial activity. Compared with the other two type strains, Staphylococcus aureus has a high resistance to modified $\mathrm{ZnO}$ nanomaterial. The main reason is that the carotenoid in Staphylococcus aureus enhances the resistance to $\mathrm{ZnO}$ oxidation stress to a certain extent.

To verify the safety of applying the prepared modified material in children's furniture, this paper explores the toxicity of the material before and after pre-deposition of polydopamine to HUVECs by the CCK- 8 method. The toxicity test results (Figure 8) show that the in vitro toxicity of the modified $\mathrm{ZnO}$ nanomaterial to HUVECs is dosedependent. At a low concentration, the modified material promotes cell growth. The cytotoxicity of the modified $\mathrm{ZnO}$ nanomaterial hinges on the grain size, shape, and surface modification of its crystals. A high dose of the material greatly impacts the mitochondrial injury and apoptosis. Therefore, the modified $\mathrm{ZnO}$ nanomaterial should only be applied to children's furniture in small quantities.

\section{CONCLUSIONS}

This paper discusses the preparation of a $\mathrm{ZnO}$ nanomaterial for children's furniture, and the research and development of antibacterial property. Based on the strengths and defects of $\mathrm{ZnO}$ nanomaterial, the authors specified the principle and flow of preparing Zinc nano-array for high-temperature hard materials, and wooden plates, respectively, and analyzed the antibacterial mechanism and antibacterial performance of the zinc nano-array. Then, the enrichment of $\mathrm{ZnO}$ nanocrystals on cellulose was improved by pre-depositing polydopamine particles. Through experiments, the particle size distribution of $\mathrm{ZnO}$ nanocrystals was analyzed; the particle size and antibacterial effect of $\mathrm{ZnO}$ crystals were determined at different concentrations of the growth solution; the XRD and ATR-FTIR images were plotted for different modified material samples; the cumulative yield of the final products, namely, $\mathrm{H}_{2} \mathrm{O}_{2}$ and $\mathrm{O}_{2}^{-}$, were counted under dark conditions; the variation of minimal inhibitory concentration was plotted before and after pre-deposition of polydopamine. The experimental results show that the prepared modified material can achieve a good antibacterial performance.

Table 6. Minimal inhibitory concentrations before and after pre-deposition of polydopamine

\begin{tabular}{|c|c|c|c|c|c|c|c|}
\hline \multirow{2}{*}{ Strains } & & \multicolumn{2}{|c|}{ Escherichia coli } & \multicolumn{2}{|c|}{ Staphylococcus aureus } & \multicolumn{2}{|c|}{ Botrytis cinerea } \\
\hline & & Before & After & Before & After & Before & After \\
\hline \multirow{10}{*}{$\mathrm{ZnO}$ suspension concentration $(\mathrm{mg} / \mathrm{L})$} & 10 & + & + & + & + & + & + \\
\hline & 20 & + & - & + & + & + & + \\
\hline & 30 & + & - & + & + & + & - \\
\hline & 40 & - & + & + & + & + & - \\
\hline & 50 & - & - & + & - & + & + \\
\hline & 60 & + & + & + & + & + & + \\
\hline & 70 & + & - & - & - & + & + \\
\hline & 80 & + & - & + & + & + & - \\
\hline & 90 & + & - & + & - & - & - \\
\hline & 100 & + & - & + & + & + & - \\
\hline Positive reference & & + & + & + & + & + & + \\
\hline Negative reference & & - & - & - & - & - & - \\
\hline
\end{tabular}




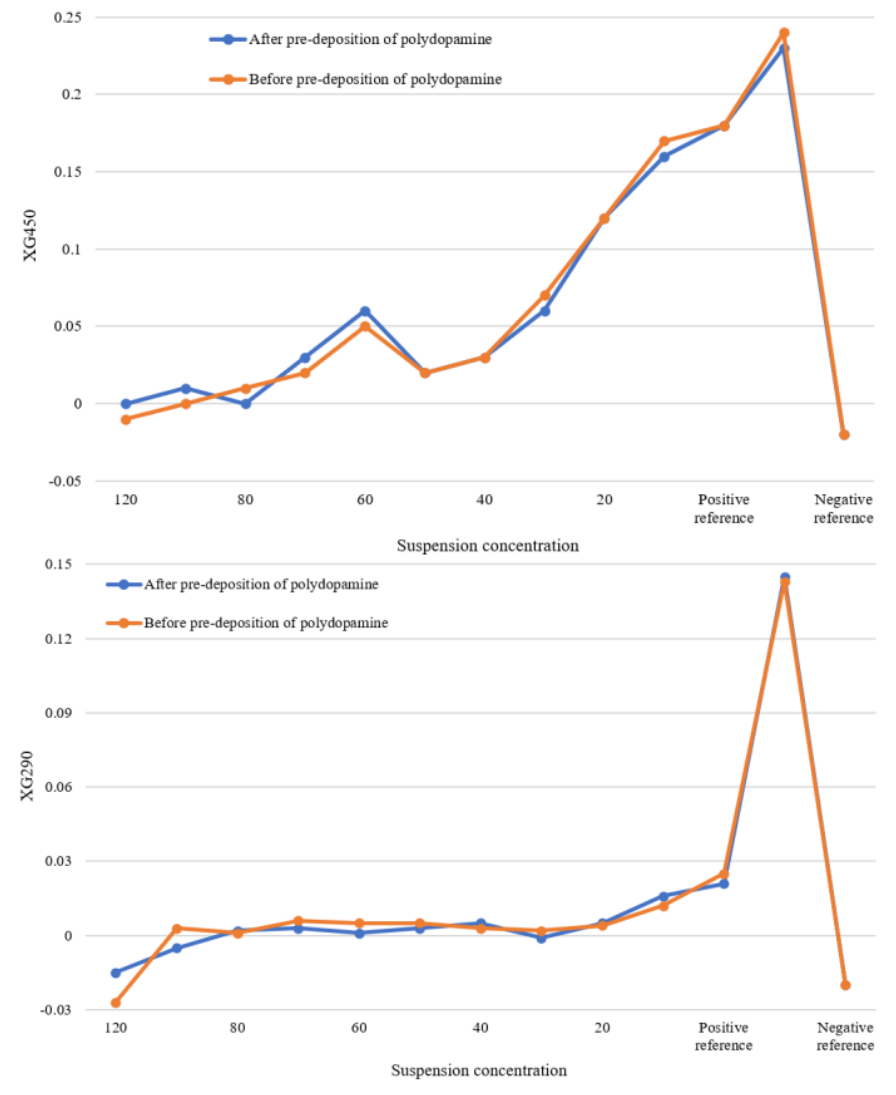

Figure 7. The variation of minimal inhibitory concentration before and after pre-deposition of polydopamine

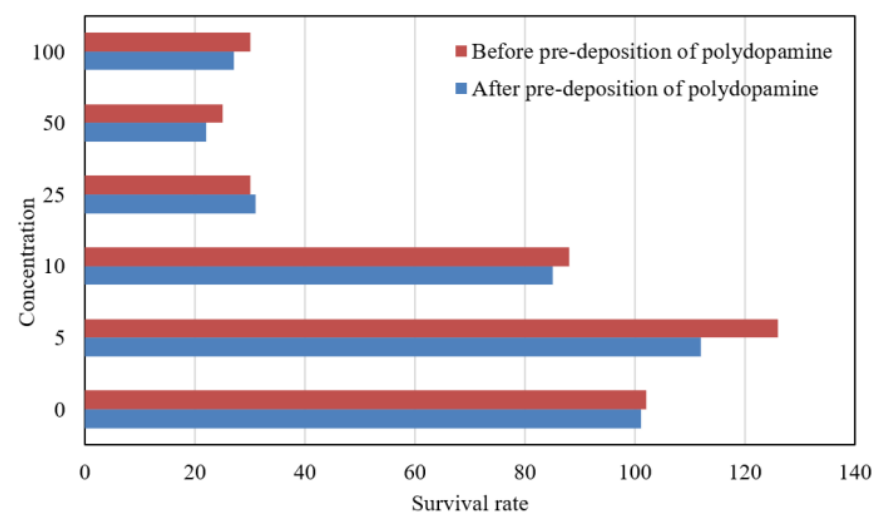

Figure 8. Toxicity test results of modified material on human umbilical vein endothelial cells (HUVECs)

\section{REFERENCES}

[1] Christian, Y., Sahroni, T.R. (2020). Green productivity methodology for furniture industry. IOP Conference Series: Earth and Environmental Science, 426: 012159. https://doi.org/10.1088/1755-1315/426/1/012159

[2] Xu, X., Hua, Y., Wang, S., Xu, G. (2020). Determinants of consumer's intention to purchase authentic green furniture. Resources, Conservation and Recycling, 156: 104721 . https://doi.org/10.1016/j.resconrec.2020.104721

[3] Xu, X., Wang, S., Yu, Y. (2020). Consumer's intention to purchase green furniture: Do health consciousness and environmental awareness matter? Science of the Total Environment, 704: https://doi.org/10.1016/j.scitotenv.2019.135275
[4] Zhang, X. (2013). Furniture design based on green ecological environment. In Informatics and Management Science II, pp. 283-289. https://doi.org/10.1007/978-14471-4811-1 38

[5] Scheithauer, U., Schwarzer, E., Tscharntke, F., Schmidt, T., Jegust, S., Richter, H.J., Moritz, T., Michaelis, A. (2015). New lightweight kiln furniture made by combination of ceramic green tapes and extrudates. Interceram-International Ceramic Review, 64(4): 204208. https://doi.org/10.1007/BF03401124

[6] Dotson, S. (2015). Green furniture: An assesment of furniture society member work. Journal of Green Building, 10(3): 47-66. https://doi.org/10.3992/jgb.10.3.47

[7] Han, J., Li, J., Jiang, Y., Wang, L. (2021). Application of innovative technology in children furniture design. In E3S Web of Conferences, 236: 04059. https://doi.org/10.1051/e3sconf/202123604059

[8] Jiang, L., Cheung, V., Westland, S., Rhodes, P.A., Shen, L., Xu, L. (2020). The impact of color preference on adolescent children's choice of furniture. Color Research \& Application, 45(4): 754-767. https://doi.org/10.1002/col.22507

[9] Dai, L., Xu, B. (2019). Research on the furniture design criteria for children's psychological development in home environment. In International Conference on Human-Computer Interaction, Orlando, FL, USA, pp. 277-286. https://doi.org/10.1007/978-3-030-23538-3 21

[10] Wan, M., Zhang, Y., Ye, W. (2018). Consumer willingness-to-pay a price premium for eco-friendly children's furniture in Shanghai and Shenzhen, China. Forest Products Journal, 68(3): 317-327. https://doi.org/10.13073/FPJ-D-17-00050

[11] Deng, T., Sun, W., Zhang, R. (2018). Research on parentchild interaction system of intelligent children's furniture based on application behavior analysis. International Conference on Intelligent Human Systems Integration, Dubai, United Arab Emirates, pp. 633-638. https://doi.org/10.1007/978-3-319-73888-8_98

[12] Ekaterinushkina, A.V., Zhdanova, N.S., Mishukovskaya, J.I. (2018). Study of functional features of furniture and equipment in the design of recreation of children's polyclinics. IOP Conference Series: Materials Science and $\quad$ Engineering, 463(3): 032028. https://doi.org/10.1088/1757-899X/463/3/032028

[13] Andaç, T., Güzel, A. (2017). Attitudes of families with children towards eco-friendly designed furniture: Kayseri sample. BioResources, 12(3): 5942-5952. http://doi.org/10.15376/biores.12.3.5942-5952

[14] Lu, C.W., Lu, J.M. (2017). Evaluation of the Indonesian National Standard for elementary school furniture based on children's anthropometry. Applied Ergonomics, 62: 168-181. https://doi.org/10.1016/j.apergo.2017.03.004

[15] Dsingh, A. (2017). Degree of musculoskeletal pain and other discomforts experienced by school children using different type of furniture during class. International Conference on Research into Design, Guwahati, India, pp. 893-903. https://doi.org/10.1007/978-981-10-3518$0 \_77$

[16] Wan, M., Toppinen, A. (2016). Effects of perceived product quality and lifestyles of health and sustainability (LOHAS) on consumer price preferences for children's furniture in China. Journal of Forest Economics, 22: 5267. https://doi.org/10.1016/j.jfe.2015.12.004 
[17] Yuan, Z.Y., Lei, Y.F., Dong, H., Meng, F.L. (2021) Sensitivity analysis of $\mathrm{ZnO}$ nanometer gas sensor based on dynamic temperature modulation. Journal of Northeastern University (Natural Science), 42(4): 469477. https://doi.org/10.12068/j.issn.10053026.2021.04.003

[18] Hermida-Montero, L.A., Paraguay-Delgado, F., Cruz, L. F., Carrillo, D., Mtz-Enriquez, A.I., Pariona, N. (2021). The role of coating and size of $\mathrm{ZnO}$ nanoparticles on the antifungal activity against Raffaelea species. Materials Letters, 301:

130314. https://doi.org/10.1016/j.matlet.2021.130314

[19] La, D.D., Nguyen-Tri, P., Le, K.H., Nguyen, P.T., Nguyen, M.D.B., Vo, A.T., Nguyenh, M.T.H., Chang, S.W., Tran, L.D., Chung, W.J., Nguyen, D.D. (2021). Effects of antibacterial $\mathrm{ZnO}$ nanoparticles on the performance of a chitosan/gum Arabic edible coating for post-harvest banana preservation. Progress in Organic
Coatings,

151:

106057.

https://doi.org/10.1016/j.porgcoat.2020.106057

[20] Li, C., Wang, C., Li, Z., Cao, Z., Xie, Y., Xue, M., Zhao, J. (2021). Preparation of $\mathrm{ZnO}$ nanoparticle/acrylic resin superhydrophobic coating via blending method and its wear resistance and antibacterial properties. Materials, 14(14): 3775. https://doi.org/10.3390/ma14143775

[21] Tuong, V.M., Huyen, N.V., Kien, N.T., Dien, N.V. (2019). Durable epoxy@ ZnO coating for improvement of hydrophobicity and color stability of wood. Polymers, 11(9): 1388. https://doi.org/10.3390/polym1 1091388

[22] Pang, S., He, Y., Zhong, R., Guo, Z., He, P., Zhou, C., Xue, B., Wen, X., Li, H. (2019). Multifunctional $\mathrm{ZnO} / \mathrm{TiO}_{2}$ nanoarray composite coating with antibacterial activity, cytocompatibility and piezoelectricity. Ceramics International, 45(10): 1266312671. https://doi.org/10.1016/j.ceramint.2019.03.076 